\title{
Consciousness and integrated energy differences in the brain
}

\author{
Robert Pepperell \\ Fovolab, \\ Cardiff Metropolitan University, \\ Cardiff, CF5 2YB, UK. \\ [rpepperell@cardiffmet.ac.uk] \\ Journal: Frontiers in Psychology \\ Research Topic: Neo-Naturalist Approaches to Consciousness \\ Publication status: Pre-submission, not peer reviewed
}

\begin{abstract}
To understand consciousness within the framework of natural science we must acknowledge the role of energy in the brain. Many contemporary neuroscientists regard the brain as an information processor. However, evidence from brain imaging experiments demonstrates that the brain is actually a voracious consumer of energy, and that functionality is intimately tied to metabolism. Maintaining a critical level of energy in the brain is required to sustain consciousness, and the organisation of this energy distinguishes conscious from unconscious states. Meanwhile, contemporary physicists often regard energy as an abstract mathematical property. But this view neglects energy's causal efficacy and actuality, as identified by Aristotle and later appreciated by many important biologists, psychologists and physicists. By reconsidering the nature of energy and recasting its role in neural activity, we arrive at a theory of consciousness that is consistent with the laws of physics, chemistry and biology. The argument draws on the integrated information theory (IIT) developed by Tononi et al. but reinterprets their findings from the perspective of energy exchange. In IIT, the conscious state in a system, such as a brain, is defined by the quantity of integrated differences, or information, it contains. According to the approach outlined here, it is in the nature of energy to manifest differences of motion and tension. The level of complexity of the energy differences in a system determines its conscious state. Consciousness occurs because, in Nagel's terminology, there is 'something it is like' to be a sufficiently complex state of energy differences.
\end{abstract}

Keywords: Consciousness, metabolism, energy, brain, information theory

\section{Introduction}

This paper aims to outline how, in principle at least, consciousness can be accounted for naturalistically, that is, within the laws of biology, physics and chemistry. Tononi et al. (2016) have addressed this question using the integrated information theory (IIT) framework. In IIT, the brain is treated as an information processing system, and consciousness is said to result from the integration of information. However, basing a theory of subjective experience on information processing may be problematic if, as has been argued, information is itself subjective (von Foerster, 2003; de-Wit et al., 2016), an intuitive concept (Erra et al., 2016) or a potentially misleading metaphor (Werner, 2011). Here, I stress the causal role of energy in biological processes and, more specifically, the way in which energy actuates differences in the world and our conscious experiences. This approach to energy may usefully complement the current information-theoretic approaches. 
Energy is of fundamental importance to biological systems. As Harold Morowitz, a biophysicist, put it, 'the flow of energy through a system acts to organize that system' (Morowitz, 1979). The action of light, chemical reactions, electricity, mechanical forces, heat, motion and tension can all be described in terms of energy (Chaisson, 2001; Morowitz and Smith, 2007; Smil, 2008) and so can the metabolic processes in the brain (Magistretti, 2008; Perez Velazquez, 2009). It is surprising, therefore, that energy receives little attention in neuroscientific and psychological studies of consciousness. Energy is neither listed in the INS Dictionary of Neuropsychology and Clinical Neurosciences (Loring, 2015) nor in the Oxford Companion to the Mind (Gregory, 2004) or the Oxford Dictionary of Psychology (Colman, 2015). Leading scientific theories of consciousness either do not reference it (e.g. Crick and Koch, 2003; Edelman et al., 2011; Dehaene, 2014; Oizumi et al., 2014), assign it only a marginal role (Hameroff and Penrose, 2014) or treat it as an information-theoretical quantity (Friston, 2013). If it is referenced, it is usually in relation to analysis of the metabolic activity that supports neural information processing (Sterling and Laughlin, 2017); however, it is seldom regarded as playing a direct functional role in the generation of conscious experience.

This lack of attention in consciousness research is all the more surprising, as some of the earliest and most influential neurobiologists, psychologists and physiologists gave energy a central place in their theories, including Johannes Müller (Otis, 2007), Hermann von Helmholtz (in Cahan, 1995), Gustav Fechner (Fechner, 1905), Sigmund Freud (Gay, 1998), William James (James, 1907), Richard Semon (Semon, 1921), Charles Spearman (Spearman, 1950), Carl Jung (Jung, 1969) and Charles Sherrington (Sherrington, 1955), as well as key figures of the Gestalt school of psychology (e.g. Eysenck, 1942) and Hans Berger, the pioneer of electroencephalography (Niedermeyer and Lopes da Silva, 1987). [For further discussion, see Pepperell (2018)]. Some recent work has investigated the connection between energy, neurobiology and consciousness (Annila, 2016) and explicitly link thermodynamics to information theory within the context of neuroscience (Collell et al., 2015; Tozzi et al., 2016; Street, 2016). The present paper builds on this work by proposing a naturalistic explanation of consciousness that is consistent with the established principles of physics, chemistry and biology.

The discussion will focus on what is arguably a basic feature of conscious experience, namely visual sensation, which I define as the immediate awareness of the visual field (Gibson, 1986; Koenderink \& van Doorn, 2008). I will specifically address two questions: How is it that we experience visual sensation, and why do we experience it from a subjective point of view? Figure 1 shows a painting that depicts my uniocular visual field made in homage to Ernst Mach, who sketched a similar scene in Vienna in the 1870s (Mach, 1897; Clausberg, 2007; Pepperell, 2015). The painting depicts what I see when, fixating on my feet, I look with my left eye and draw on an iPad, which is shown in the foreground. In what way does energy contribute to my having this visual sensation? 


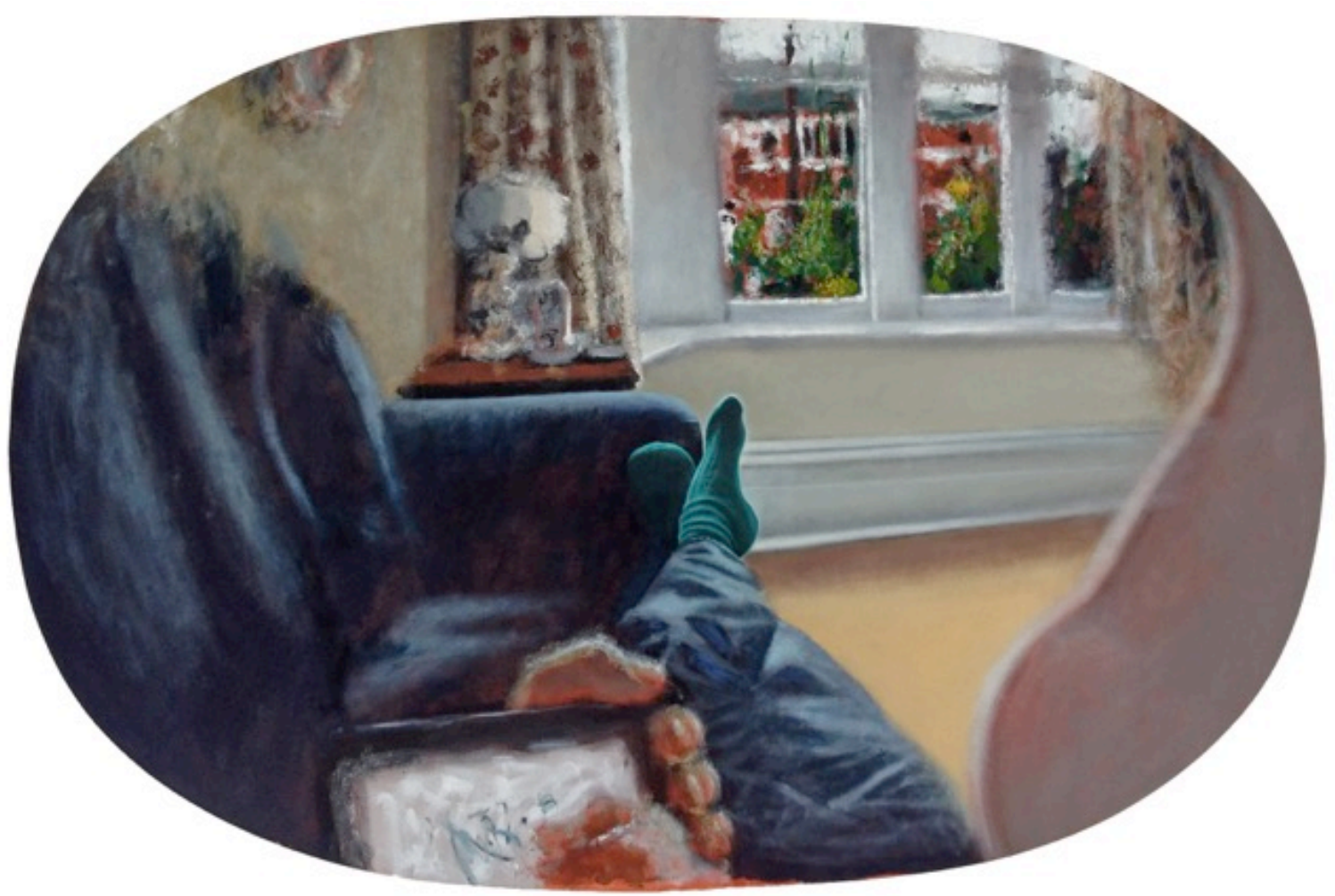

Figure 1. Self-portrait (after Mach), 2012, oil on formed canvas, $100 \mathrm{~cm}$ x $150 \mathrm{~cm}$. This painting shows the view from my left eye looking at my feet and tries to capture as accurately as possible the appearance of my entire visual field including, on the right, my nose.

\section{The role of energy in visual sensation}

We begin by following James Gibson's model of the way in which we visually perceive the environment (Gibson, 1986). Gibson, who also drew versions of his egocentric perspective based on Mach's drawing (Gibson, 1950/1986), identified the 'radiant light' as the 'sea of physical energy' in which we are immersed, and which is generated by light sources (natural or artificial) and their reflection from surfaces in the environment. Packets of electromagnetic energy carried by photons of differing intensity and wavelength move in diverse directions through the environment. The configuration of the radiant light is immeasurably complex and lacks any objective or determinate structure until it is observed or measured from some point of view, that is, by a spectator (Feynman, 1985; Gibson, 1986; Pepperell, 2006; Koenderink, 2014).

A very small subset of photons, those that travel at a particular angle with respect to the pupil of my eye and fall within my visual field, enter the chamber of my eye to strike my retina. Gibson called this the 'ambient light'. My visual sensation of the scene begins with the phototransduction of the electromagnetic energy that was received by the retina. The minimum flux of light energy that the eye can detect has been estimated to be in the region of $10^{-9} \mathrm{erg}$ per second, which is a testament to the extraordinary sensitivity of human eyes (Pirenne, 1967). Some of the energy that strikes the retina will collide with the receptor discs in the light-sensitive cells of the eye, the rods and cones, and will be absorbed by a photopigment that contains retinal, a chromophore molecule coupled to various opsin proteins that are sensitive to different wavelengths of light. In the case of rods, which 
contain the photopigment 'rhodopsin', the absorption of energy in the photon alters the molecular structure of the retinal by isomerisation from 11-cis retinal to all-trans-retinal (Levine, 2000). At the point of phototransduction, the electromagnetic energy in the photon is transferred to the retinal to perform the mechanical work of straightening a bend in the chain of carbon atoms.

The reconfiguration of the retinal molecule causes it to break free from the opsin with which it was coupled and trigger a cascade of chemical reactions, leading to a change in the polarity of the cell membrane. It is an unusual feature of vertebrate photoreceptors that they are hyperpolarised by light absorption, whereas the receptor cells in other sensory modalities are depolarised by stimulation. This means that photoreceptors have a low rate of neurotransmitter release from the synaptic terminals when excited and a higher rate when not excited. Consequently, more energy is consumed by photoreceptors in the dark than when they are exposed to light (Wong-Riley, 2015). However, what is important from the point of view of the organism's ability to detect light is that that the photoreceptors vary the rate at which they release neurotransmitters according to the intensity of the light energy received rather than the particular polarity (Levine, 2000).

In addition to absorbing energy from the environment, sensory processes require the contribution of energy from within an organism. The energy needed for photoreception is sourced mainly from the oxidisation of glucose. This energy is consumed primarily in transporting ions across the cell membrane to restore polarisation after excitation (WongRiley, 2010). Energy consumption, or the metabolic rate, can be measured in vivo with techniques that monitor changes in the flow of the blood supplying glucose and oxygen to cells (Shulman and Rothman, 2005). While all neural activity is energetically demanding - the human brain consumes some $20 \%$ of the body's total energy resource while constituting only $2 \%$ of its mass (Magistretti, 2008) - the oxygen requirements of the mammalian retina exceed even that of the brain (Ames et al., 1992).

The change in the polarity of the cell membrane of the photoreceptor initiates a long and highly complex chain of electrochemical reactions that pass energy-driven impulses along the bipolar and ganglion cells to the optic nerve that connects the eye to the lateral geniculate nucleus (LGN) and the visually responsive areas of the cortex (Levine, 2000). In each of these stages, the cells generate action potentials that are sustained by a variety of metabolic processes, even though far less is known about their precise operation than in retinal activation (Wong-Riley, 2010). We do know, however, that throughout the visual system's energy metabolism, neural activity and sensory excitation are tightly coupled, and that the metabolic load increases as a function of stimulus complexity (Alvarez-Linera Prado et al., 2007; Wong-Riley, 2010). Measures of the local cerebral metabolic rate in the human visual cortex have been shown to increase progressively from a baseline condition in which eyes are closed through exposure to visual stimuli of increasing complexity with metabolic rates increasing faster in the associative cortex than in the primary visual cortex (Phelps et al., 1981). There is also evidence that the act of exposing rats to complex visual stimuli promotes the formation of new blood capillaries that are necessary for increased energy consumption (Black et al., 1987).

Given that there are around 130,000,000 photosensitive rods and cones in each human retina (Osterburg, 1935) that are served by millions of ganglion and epithelial cells with hundreds of thousands of axons in the optic nerve activating many more millions of neurons in the visual cortex, the biochemistry involved in even the simplest visual 
sensation is vastly complicated. At each stage, however, the metabolic processes that consume and exchange energy will drive the activity. In the cortex, much of this energy (up to $80 \%$ ) is consumed through the work of the repolarising neurons (Sibson et al., 1998). What then is being achieved by this voracious consumption of energy in the brain, much of which is due to visual processing, and which comes at a high cost for the organism in terms of its overall energy resource? An obvious advantage for the organism is that it enables the recognition of environmental objects from the light energy that they emit or reflect. This environmental light energy, as noted above, reaches the eye in a pattern that is determined by the environmental conditions. A predator, for example, will present a different pattern of light energy from its background. The visual system allows an organism to discriminate one from the other. How is this done?

\section{The role of visual sensation}

The differentiated intensities and wavelengths of environmental electromagnetic energy that reach the eye - what Gibson called the 'ambient optic array' - are distributed across the retinal surface and differentially stimulate photoreceptors. This generates correlated activity at the ganglion cell level, which is relayed via the LGN to the visual cortex. At each stage, the initial pattern of excitation undergoes multiple layers of filtering that progressively differentiate visual features, such as objects' edges, colours and depths (Hubel and Livingstone, 1987). An example of this differential filtering can be seen in the antagonistic center-surround with respect to the organisation of retinal ganglion cells. Such cells, which are ubiquitous in the visual system, form a miniature receptive field that can respond to variations in the pattern of the stimulus (Palmer, 1999). For example, if both the centre and the surround of the field are stimulated, then excitation will not occur. If, however, only the centre is stimulated and not the surround, then action potentials will be generated. In this way, the visually responsive cells can discriminate and enhance contrasts of light and, when acting in concert across large areas, can respond selectively to differences in the overall pattern of retinal stimulation. Due to the same process, homogeneous stimuli do not excite a response (Levine, 2000).

Differential stimulation across the retina evokes responses in various regions of the visual cortex, resulting in a topographic map that describes the location of correlated activation within the brain (Alyssa and Barton, 2012). The layout of this map can be quite accurately determined by selectively stimulating the visual field and measuring patterns of neural activation in areas of the visual cortex using functional magnetic imaging techniques, such as fMRI. In many cases, there is a one-to-one correspondence between the locations in the visual field and locations in the cortex, even though it is likely that these vary considerably between individuals (Silver and Kastner, 2009). As fMRI methods indirectly measure the increases in cellular metabolism over baseline in localised regions, it follows that the stimulation of the visual field results in increases in localised energy consumption in the cortex (Shulman, 2013). One of the primary effects of visual sensation, therefore, is the creation of patterns of differential energy activity that are topographically distributed across the brain and mapped to the layout of the visual field.

It remains unclear, however, in what way those measurable patterns of energy activation in the brain lead to the subjective experience of objective structures in the environment. It is tempting to think that the retinotopic map in the brain is a veridical index of what exists in the world or at least of the properties of the light energy that we absorb from it. However, we have known since the nineteenth century that features, such as colour, that 
appear to be part of the physical world are, in fact, subjectively generated and not present in the environment (Helmholtz, 1878. In Cahan, 1995). In addition, we cannot directly sense the energy absorbed by the body through the sense receptors. Johannes Müller demonstrated, followed by Hermann von Helmholtz, that what we perceive through vision, as in the case of other sensory modalities, is the result of energetic excitations generated by the body - what Müller called 'specific nerve energies' - that are only indirectly linked to the variations in energy that impinge on us from the world outside (Otis, 2007; Bridges, 1912). More recently, it has been argued that vision functions as a kind of 'user interface' between the organism and the world, in which the bodily generated sensations serve as biologically useful proxies for features of the environment, but not as veridical equivalents (Hoffman et al., 2015).

We can apply this line of argument to features of visual perception, such as edges or lines, which are often said to be 'detected' by the visual system, as if they are objective features of the world that are documented in perception (Marr, 1980). However, Koenderink (2014) has argued that this is spurious. The visual system does not detect edges or lines, but rather it defines or creates them based on the discriminations made between levels of contrast in the patterns of light. Illusory contour effects, such as can be seen in the Kanizsa triangle, demonstrate the capacity of the visual system to create visual features that have no environmental equivalents (Kanizsa, 1974). Variations of light energy are only formed into an image at the viewer's point of perspective, when a small subset of all available light converges in the eye. The same edge or line may not appear when viewed from a different position or with perceptual apparatus that belongs to a different creature (Baluška and Mancuso, 2009). From this we observe a basic principle of vision, which is that environmental features acquire their visual form only through the relationship (what Gibson called the 'reciprocity') between environmental conditions and the sensory apparatus of the perceiving organism.

It is also important to recognise that in addition to emphasising the discontinuities in received energy, the visual system also integrates these myriad differences into a coherently structured visual experience. It is thought that this is achieved by combining bottom-up sensory data with attention-driven top-down influences to create saliency maps that topographically represent the features within the visual space of behavioural relevance to organisms (Treue, 2003). Recent work has drawn attention to the significance of lateral connection strength between neurons in the visual cortex and the spatial relations between locations in the visual field (Song et al., 2017). By repeatedly presenting two-point stimuli in the visual field, the authors showed that the local strengthening of lateral connections leads to a contraction in the perceived distance between the stimuli. Therefore, these lateral connections may underlie in the integrated topological structure of visual space.

The visual sensation I experienced, and depicted in the painting, is an example of how vision functions as an energy-driven 'difference engine', the work of which is to create differentiations within neural pathways and regions of cortex that are usefully correlated with differentiations in energy in the environment - at least those that my perceptual apparatus was able to register. Gibson summarised this idea as follows: 'the registering of differences of intensity in different directions is necessary for visual perception' (Gibson, 1986). At the same time, these differences do not exist in isolation from each other, as independent events, but constitute an integrated structure, which I experience as the totality of my visual field. In short, visual sensation is differentiated and integrated (Edelman et al., 2011; Tononi, 2012). When and how this integrated differential activity 
translates into conscious awareness of what we see remains largely mysterious, and it forms the subject of much intensive study (Tononi, 2012; Daheane, 2014; Koch et al., 2016). What tends to be neglected in such studies, however, is the critical role of energy.

\section{The relationship between consciousness and energy in the brain}

The role of energy in brain activity is now studied mainly in terms of cellular metabolism and the efficiency of information processing. As noted, the brain is a voracious consumer of energy in comparison to the other systems of the body (Allaman and Magistretti, 2013). Most of this energy is derived from the oxidization of glucose. Glucose and oxygen are delivered to the cerebral tissue through the blood. Roy and Sherrington were the first to propose a direct correspondence between the changes in blood flow and neural activation (Roy and Sherrington, 1890). Many features of human brain anatomy, such as the amount of blood vessels per unit of space, the lengths of neural connections, the width of axons, and even the ratio of brain to stomach size are thought to be determined by the high metabolic demands that are associated with complex cognitive processing (Allen, 2009). Much of this energy is consumed in re-establishing the ion gradients in neurons after regulating action potentials and maintaining the synaptic currents (Laughlin, 2001; Attwell and Laughlin, 2001).

It is widely thought that the purpose of energy that is supplied to the brain is to fuel the neural signalling mechanisms that carry out information processing (Magistretti, 2013; Sterling and Laughlin, 2017). In this 'computational' view of brain function, each neuron is essentially conceived as a digital messenger, that is, a binary 'all-or-none' switch that processes signals from its neighbouring neurons (McCulloch and Pitts, 1943; Sterling and Laughlin, 2017). The achievement of the optimum 'signal-to-noise ratio' to support rapid information processing in the human brain requires a delicate balance between energy supply and circuit design. For example, it is thought that energy supply places an upper 'speed limit' on neural processing of about $1 \mathrm{kHz}$ (Attwell and Gibb, 2005). Metabolic activity in the brain is, therefore, regarded as subservient and is considered to bound information processing, with no direct functional role in consciousness.

Among the few neuroscientists who proposed a functional role for energy in sustaining consciousness are Shulman et al. (2009), who have argued that the level and distribution of cerebral energy consumption can be correlated with levels of consciousness (Shulman, 2013). By studying the progressive loss of behavioural response to external stimulus from wakefulness to deep anaesthesia, they pointed to a corresponding reduction and localisation in cerebral metabolism as being indicative of the necessary role of high global metabolism in consciousness. However, they are also clear that high baseline metabolic rates are not sufficient for consciousness, as patients with locked-in-syndrome and those who suffer from some forms of epileptic seizures can register high levels of global brain metabolism, but without exhibiting the observable behaviour that we expect from a conscious person (Shulman, 2013; Bazzigaluppi et al., 2017). This hypothesis has been challenged on several grounds, including that behavioural responsiveness is inadequate as a measure of consciousness, given that signs of awareness have been detected in some people who have diagnosed as being in a vegetative state and/or having a low cerebral metabolism (Owen et al., 2006; Seth, 2014). Moreover, some patients who recover from a vegetative state to regain consciousness do so despite having substantially reduced cerebral metabolism compared with normal controls (Laureys et al.,1999; Chatelle et al., 2011). 
There is further evidence that the relationship between metabolic rate and consciousness is not straightforward. Energy consumption during non-rapid eye movement sleep drops to just $\sim 85 \%$ of that in the waking state. During rapid eye movement sleep, energy consumption can be as high as in the waking state (Dinuzzo et al., 2017). At the same time, consciousness can be minimally sustained with energy consumption at only $42 \%$ of the level that occurs in health-conscious individuals, suggesting that much cerebral metabolic activity in normal waking states does not functionally contribute to consciousness (Stender et al., 2016). Meanwhile, most anaesthetic agents obliterate consciousness by inhibiting glutamate neurotransmitter activity with a corresponding global reduction in cerebral metabolism. Ketamine, on the other hand, increases brain metabolism, yet it can still cause loss of responsiveness (Pai and Heining, 2007; Shulman et al., 2009).

In recent years there has been a growing interest in intrinsic brain activity (Clarke and Sokoloff, 1999; Raichle, 2011). This 'background' or spontaneous activity occurs in the resting state, in the absence of external stimulation or directed attention, and its energy consumption greatly exceeds that of localised consumption due to task performance or attention, often by more than $95 \%$. The discovery of this so-called 'dark energy' in the brain was greeted with some surprise in the neuroscience community and remains controversial (Morcom and Fletcher, 2007; Raichle, 2010). As mentioned above, Shulman stressed the importance of high baseline energy in sustaining consciousness and, like Raichle, challenged the widespread tendency in neuroscientific studies to disregard intrinsic or baseline energy in favour of studying localised activation due to stimulation of the evoked responses (Shulman, 2013).

Also surprising has been the discovery that a default mode network in the brain - a set of interconnected regions associated with intrinsic activity - consumes high levels of energy when a person is in the non-attentive resting state, but that energy consumption decreases significantly when a more cognitively demanding task, such as paying attention to a stimulus, is performed (Shulman et al., 1997; Raichle et al., 2001). Evidence from patients with disorders of consciousness implicates the connectivity of the default mode network in sustaining consciousness (Vanhaudenhuyse et al., 2009), whereas impaired awareness is associated with decreased metabolism in these regions (Laureys et al., 1999). It has also been proposed that deactivation of the default mode network may act as a marker of consciousness (Crone et al., 2011).

Estimates of the additional energy required to support conscious perception of stimuli compared to those not consciously perceived show only a modest increase of $6 \%-11 \%$ (Schölvinck et al., 2008). This followed from previous work in mammals showing that ongoing spontaneous activity in the brain is only weakly modified by visually evoked response (Fiser et al., 2004). Schölvinck et al. suggest their findings reflect an evolutionary strategy for economising on energy consumption which exploits the fact that information can be encoded both by increasing and decreasing neural firing rates. One consequence of this for functional imaging studies which measure increases in blood flow correlated with stimulation is that functionally relevant decreases in firing will not be detected.

From this evidence, we can find a strong connection between metabolic activity in the brain and the presence of consciousness; thereby, when metabolic rates fall below a critical level, consciousness ceases (Laureys, 2005). However, there is no simple positive 
correlation between the level of brain energy consumption and level of awareness, as is shown in cases of epileptic seizures in which metabolic rates can be high. Neither can we point to a simple correlation between localisation of metabolic activity and the presence of consciousness, given what we know about intrinsic or baseline activity. Overall, this presents a difficult picture from which to understand the functional relationship between energy, neural activity and consciousness in the brain.

\section{Consciousness and energy organisation}

An alternative, or perhaps complementary, way to think about this issue is in terms of how the energy activity in the brain is organised rather than its global level or specific location. Indeed, this has implicitly been the focus of recent research that aims to provide quantitative measures of consciousness. In one study, the researchers used transcranial magnetic stimulation (TMS) to send a magnetic pulse through the brains of healthy controls and patients with various states of impaired consciousness (Casali et al., 2013). By measuring how the pulse perturbed neuronal networks, the researchers were able to determine the relative complexity and extent of the pathways through which the pulse propagated and correlated these to levels of consciousness. The researchers calculated a perturbation-complexity index (PCI) for each case to be able to discriminate between the levels of consciousness clearly. This method was further validated as a reliable objective measure of levels of consciousness by Casarotto et al. (2016).

The PCI was calculated using data from electroencephalographic (EEG) measurements of the cerebral perturbation following the TMS. Images from the EEG were filtered into binary data that was then quantified using a Lempel-Ziv algorithm, a widely used information-theoretical technique in which complexity is measured as a function of data string compressibility, with more complex data strings being less compressible (Ziv and Lempel, 1977, Aboy et al., 2006). The results of this study were presented as providing a measure of complexity in terms of information integration across multiple brain regions, with wakeful consciousness exhibiting a 'high degree of differentiation of the activity localized within separate regions' (Schiff, 2013). The notion that levels of consciousness can be quantified according to the amount of information integration and differentiation present in cerebral structures is of central importance to the IIT approach, as championed by Tononi (2012; see also Edelman et al., 2011).

However, we could apply the same procedure to analyse the behaviour of energy in the brain as is applied to measure its putative information content. Energy states fluctuate within the brain, both in response to external stimulation and due to intrinsic activity. Energetic differentials exist at the molecular and cellular level and at higher levels of organisation, such cellular networks, within or between local anatomical regions and across global structures. They are routinely detected at varying degrees of spatial and temporal resolution by neuroimaging techniques, such as positron emission tomography (PET), functional magnetic resonance image (fMRI) and EEG (Shulman, 2013; Bailey et al., 2005; Niedermeyer and Lopes da Silva, 1987). Referring again to the study by Casali et al. (2013), the perturbations from which the PCI was calculated were generated by a pulse of magnetic energy from the TMS and were imaged with EEG that measures electrical voltage differences, that is, fluctuations in potential energy between clusters of neurons in the cortex (Niedermeyer and Lopes da Silva, 1987; Hu et al., 2009; Koponen et al., 2015). The aspect that was, in fact, measured in vivo was not information as such, but the complexity of the distribution of the energy pulse from the TMS through the 
cerebral tissue via the conduits of the neurons and their patterns of connectivity. Energy distribution complexity, therefore, could be defined as the quantity of energetic integration and differentiation in the same way as information content is in the PCI.

Other researchers have developed similar information-theoretical methods to those used by Casali et al. for quantifying the complexity of brain activity and levels of consciousness. King et al. (2013) analysed data from 181 EEG recordings of patients who were diagnosed with varying states of impaired consciousness and applied a measure of weighted symbolic mutual information (wSMI) that sharply distinguished between patients in vegetative state (VS), minimally conscious state (MCS) and conscious state (CS). As these data are derived from EEG measurements they could also be interpreted as measures of energy distribution complexity. There is long-standing evidence of the connection between EEG and brain metabolism and, hence, energy transactions (Ingvar, 1971; Kuschinsky, 1993; Alkire, 1998; Boord et al., 2007). Erra at al. (2016) proposed a causal connection between information complexity in the brain and consciousness, which they determined using data collected via magnetoencephalography (MEG), intracranial EEG (iEEG) and scalp EEG. But they explicitly noted the equivalence between information exchange, as understood in neuroscience, and energy transactions in neurobiological processes (see also Perez Velazquez, 2009).

Meanwhile, recent research has directly investigated the connection between metabolism, brain organisation and levels of consciousness by combining EEG measures with PET, a more specific measure of cerebral metabolic activity. Chennu et al. (2017) collected data from 104 patients in varying states of conscious impairment using both techniques and from this determined a metric that indexed the densely interconnected hubs of activity across widely distributed brain regions that discriminated levels of consciousness to a high degree of accuracy. The authors summarised as follows: 'These results represent strong evidence of the correlation between the presence of highly active and interconnected hub nodes in functional brain networks measured at the bedside by EEG, and the energy demands of these hubs, as measured with PET.' This study was built on previous work by Demertzi et al. (2015) that used fMRI to correlate a measure of intrinsic functional connectivity in the brain with levels of consciousness. The PCI method has also been further validated by a study combining EEG and ${ }^{18} \mathrm{~F}$-fluorodeoxyglucose (FDG)PET (Bodart et al., 2017), so reinforcing the connection between levels of consciousness and the organisation of metabolic activity in the brain.

Measures, such as PCI, wSMI and intrinsic functional connectivity, offer evidence that it is not the total amount of energy in the brain or its localisation that correlates with consciousness but the complexity of the organisation of energy (measured as metabolic activity) in terms of its differentiation and integration. As an alternative, or complement, to the view that the brain is an information processing machine, we can think of it as a biological system for generating energy differences of immense diversity that are at the same time deeply integrated across wide anatomical regions. This results in patterns of energy activity that can be quantified in terms of their complexity using informationtheoretic techniques. However, it does not follow that what is being processed in the brain is only information. The widely held assumption that the role of energy in the brain is to metabolically subserve neural activity for the purpose of information signaling and computation may need to be revised. Instead, we might regard the purpose of neural processes as being to distribute and regulate energy in an efficient and highly organised way to enable the operation of biological functions, such as visual sensation. 


\section{The visual field as energetic field}

How might energetic activity in the brain enable visual sensation? Tononi (2014) has proposed a model of the 'conscious grid' to account for the neural organization that supports awareness of the visual field. This two-dimensional (2D) grid is composed of an array of physical elements that can each be in an on or off state, and which are connected via a lattice structure to their near neighbours so that they are able to communicate. The number of possible states that the grid can have specifies the number of 'first order concepts' it is capable of supporting. In a grid of $1000^{2}$ elements, this is $10^{6}$. Each state in a time sequence is probabilistically determined by the prior state and, in turn, probabilistically determines the succeeding state, thus determining the 'cause-effect repertoire' of the system as a whole. Critically, this cause-effect repertoire has the property of being 'maximally irreducible', i.e. its conceptual structure is not reducible to its sub-components. The degree of irreducibility is measured as $\Phi^{\text {max }}$. Higher orders of conceptual structure can be achieved in the system through local connections between neighbouring elements, which, in turn, can influence or be influenced by other neighbouring or more distant elements. In this way, the system can maximize its conceptual structure $\left(\Phi^{\text {max }}\right)$ from the relatively simple organization and behaviour of elements.

Tononi (2014) directly links this 2D grid model to the awareness of the visual field: 'the conceptual structure specified by such a 2D grid would be nicely suited to specify experienced 2D space which...consists of distinct spatial locations, their relative ordering, their distances, and so on, all of which are immediately given in our consciousness'. He notes that this model can also describe the topographic mapping of visual space to the regions of the brain, given that many parts of the cerebral cortex are organised in such grid-like formations. These correspond to spatial positions within the visual field, reflect varying degrees of sensitivity and acuity across the retina and map differentiated features, such as edges and orientations. These mappings not only connect the local features of the visual field to the localised brain activity but are also laterally connected to neighbouring maps in a grid-like fashion. Crucially, there is a striking resemblance between the organisation of phenomenological distinctions within experience and the way features are mapped across cortical grids. The recent study by Song et al. (2017) provides further neurological evidence of the intimate correspondence between perceived features of the visual space and the grid-like cortical connectivity.

I will elaborate on Tononi's 2D conscious grid but treat it as a system based on energy flow rather than information processing. Figure 2 is a diagram of a schematic visual system consisting of several components arranged in strata. The stratum at $A$ shows the radiant light in the environment, a field of electromagnetic energy that is of indeterminate structure until observed from some point of view. The different colours and line thicknesses indicate the variety of intensity and wavelengths of light. $B$ shows an aperture through which a limited amount of energy from $A$ - Gibson's ambient optic array - can pass to reach the photoreceptive surface at $C$. A projection is formed at $C$, which has a geometrical structure defined by the distribution of differences in wavelength and intensity of the energy passing through the aperture. The structure of this projection is not an intrinsic feature of $A$ as such, but a product of interaction (Gibson's 'reciprocity') between $A$ and $C$. $C$ is constituted by a mesh of light receptors connected to vertically oriented channels that are shown in the stratum $D$. When the input energy from $A$ reaches $C$, it is transduced from electromagnetic to electrochemical energy and passes down the channels at $D$ in varying quantities depending on the stimulus, as indicated by different line 
thicknesses. This exchange is powered by an energy reservoir at $E$. A map is formed in the stratum at $F$, which is a region of localized energetic activity that is correlated to the input energy channelled through $D$. Each map at $F$ is connected via horizontal pathways, $G$, to other maps and able to exchange energy of varying quantities. In the diagram, these are shown as pathways between neighbouring maps but could equally well cover longer ranges. The stratum at $F$ in this model, therefore, has a similar grid structure as Tononi's model.

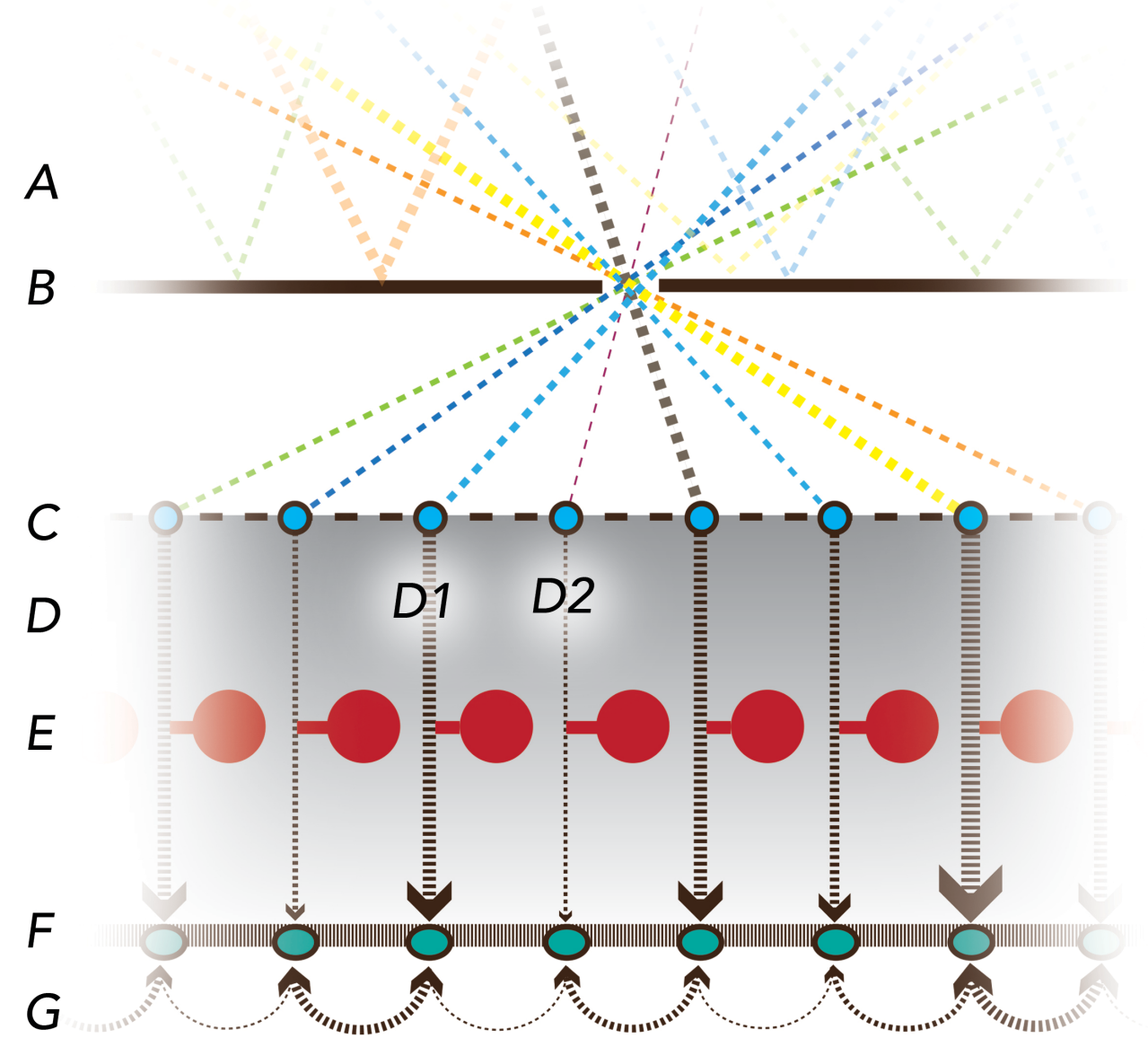

Figure 2. A diagram of a simple energetically driven visual system organised in strata. Stratum $A$ shows the radiant light, the field of electromagnetic energy located in the environment visualised as dashed lines. The different colours and line thicknesses indicate the varying intensities and wavelengths of light. The line at $B$ is a membrane with a small aperture through which only some of the light at $A$ can pass, the ambient optic array. Most of it is reflected or absorbed. The light passing through $B$ arrives at a receptive surface $C$ to project an image. The structure of the image is determined by the location of $B$ with respect to $C$, the size of the aperture and the environmental lighting conditions in $A$. The receptive surface at $C$ is composed of light receptors at the top of vertically oriented channels that occupy the stratum $D$. These react to the light energy arriving at $C$ by converting it to electrochemical energy that flows along the channels in $D$ in varying quantities, indicated by the line thicknesses, to the stratum at $F$, a process powered by energy supplied from reservoirs at $E$. A map is formed wherever each channel in $D$ meets the stratum $F$. The activity in each map correlates to the state of the energy arriving at $C$, via a channel at $D$. Horizontally oriented channels at $G$ connect the maps at $F$ together into a grid by allowing varying amounts of energy (indicated by the thicknesses of the arrow lines in $G$ ) to flow between different maps. 
Rather than treating the elements of the system such as the channels at $D$ as binary on-off switches that process information, I treat them as channels through which streams of energy flow in discrete bursts. The rate of flow (such as its intensity and frequency) is determined by the properties of the incoming energy and the structural properties of the channel itself (such as its sensitivity, bandwidth, available energy resources, and channel length). Likewise, the horizontal connections at $G$ exchange energy across the grid between the maps in such a way that each discrete vertical channel mapped to the grid can exchange energy with its neighbours, in amounts that vary in response to the amounts arriving from $D$. In the example shown, more energy is being channelled by $D 1$ than $D 2$. By summing and comparing the total quantities of energy in each map and the direction of the source, the grid at $F$ is able to both differentiate and integrate the overall pattern of energy received at $C$. As the number of energy sensitive vertical channels and horizontal connections increases, so does the total complexity of the system, measured as quantities of differentiation and integration occurring throughout.

The following summarises how the proposed grid model functions as a visual system:

1. It collects a small subset of all the available electromagnetic energy in the environment, using the aperture as a selective filter.

2. It forms a projected image with a structure that reliably correlates to, but is not identical to, differentiated states within the environment

3. It then samples the projected image, converting patterns of differentiation within the image structure into differentiated vertically-oriented streams of electrochemical energy.

4. These streams of energy are projected to structures that locally map the features of the sampled image.

5. These local maps are then integrated into a grid via horizontally-oriented energetic streams.

6. The state of the electrochemical energy in the grid correlates to the state of the electromagnetic energy arriving from the environment in a way that usefully serves the biological needs of the seeing organism.

7. The energetic activity in the grid is identical with the visual field, as perceived by the seeing organism.

8. The perceived structure of the visual field belongs to the seeing organism rather than its environment but is causally determined by the structure of its environment as well the 'cause-effect repertoire' of its own biological apparatus.

The system could be extended in ways that are structurally simple, but which would significantly expand its cause-effect repertoire. For example, another layer of maps, F2, could be added below $F$ that connects both horizontally and vertically, so that the $2 \mathrm{D}$ grid becomes a 3D matrix. Relations of difference determined between channels at $D$ could be passed to $F 2$ having been summed at $F$, in the same way the centre-surround arrangement of cells operate in the visual system to discriminate contrasts in received patterns of 
light across a receptive field. As more layers of maps $(F 3, F 4, F 5 \ldots)$ are added to the system it becomes an increasingly deep matrix. With many interconnected layers, each having a state that is causally determined and determining, the structure becomes a kind of three-dimensional medium that supports highly differentiated and integrated energetic states that correlate to patterns of light received from the environment. Imagine that within this medium there exists a three-dimensional 'image' composed of relations between energetic differences correlating to the patterns in the received light. This image has no morphological identity with the environment in itself; it does not share its physical properties. But nevertheless, it correlates to differences in that environment, observed from the system's perspective, that are relevant to and useful for the system's larger purpose, a la Hoffman's theory of vision as a user interface (Hoffman et al., 2015).

This organisation displays some of the features we might expect from a biologically useful visual system.

1. It can efficiently discriminate objects in the environment by parsimoniously sampling electromagnetic energy.

2. It establishes a causal physical relationship between the neurobiological structure of the seeing organism and the features of its environment.

3. The seeing organism can determine critical environmental properties such as object scale, distance, orientation and motion, which are all relative to it.

4. It is scalable; the sensitivity and resolution of the system can be increased using the same principles but adding more vertical and horizontal channels.

The purpose of presenting this simple model is to show how a grid-like system might function when based on energy flow rather than information processing. Crucially, it illustrates how the indeterminate structure of the ambient light array can be converted to a neurological structure, which can then be used by an organism for advantageous purposes such as guiding action. It may be possible, after further elaboration, to show how such a system could be implemented in the biology of the brain in the way Tononi (2014) has suggested using his information-based conscious grid model. However, this would still not directly address the problem of why energetic activity configured in such a way in the brain would lead to the phenomenal experience of the visual field, as depicted in Figure 1. This point can be addressed once we have given thought to the nature of the energy on which all these activities depend and its relationship to information.

\section{What is energy?}

The concept of energy that we are familiar with today emerged only slowly and fitfully from the late eighteenth century on, gaining traction through the study of thermodynamics in the nineteenth century and then finding its place at the centre of theories of relativity and quantum mechanics in the twentieth (Coopersmith, 2010). Its colloquial usage refers to loosely connected phenomena, such as vigour, vitality, power, activity and zest. In its scientific usage, however, energy is strictly defined as a measure of the capacity of a system to do work, and work, in turn, is defined as the measure of energy transfer that occurs when an object is moved over a distance by an external force, at least part of which is applied in the direction of the displacement (Duncan, 2002; Encyclopedia Britannica). 
Scientists and engineers often refer to energy as an abstract property: 'Energy is a mathematical abstraction that has no existence apart from its functional relationship to other variables' (Abbott and Van Ness, 1972. See also Rose, 1986). It is a property that can be accounted for in any reaction, but its total quantity is always conserved (Smil, 2008).

Despite the enormous amount of interest in the physics of energy and its central importance in so many branches of science, it remains, in many ways, mysterious (Feynman, 1963; Smil, 2008; Coopersmith, 2010) and has been the subject of relatively little philosophical interrogation (Coelho, 2009). From a scientific perspective, there may be little apparent need to question the current concept of energy as an abstract accounting property, given that it functions perfectly well as such in many contexts. But the magnitude and complexity of the challenge of explaining consciousness scientifically demands that we revisit all concepts, ideas and theories that may be relevant (Chalmers, 1996). Energy is one such concept. If we ask what the nature of energy is, we find no completely satisfying answer.

The origin of the energy concept in the European intellectual tradition is traced back to Aristotle, who coined, but never precisely defined, the term energeia ( $\varepsilon v \varepsilon \dot{\rho} \rho \varepsilon 1 \alpha$ ) to describe variously action, activity, actuality, being at work and being in the act of doing what something is purposed to do (Aristotle, 2002). Scholars have long debated the best way to translate this term from Greek. The word 'energy' itself has been used, as have 'activity' and 'actuality', but 'being-at-work' is currently favoured, partly due to energeia's roots in ergon, the Greek word for work (Aristotle, 1818; Ellrod, 1982; Sachs in Aristotle, 2002). Although modern scholars have tended to dissociate Aristotle's word from current usage, this ancient thought may still be of much value, when considering the nature of energy. Indeed, we can find even deeper roots for these ideas if we go back beyond Aristotle to his predecessor Heraclitus, whose cosmological view was informed by three main principles: that activity in nature is driven by 'fire' - which has been interpreted as synonymous with energy (Heisenberg, 1958) - structured by conflict or tension and subject to continual change or flux (see Sachs in Aristotle, 2002; Kahn, 1989).

What these ancient philosophers seem to be pointing to is the active, dynamic forcefulness of natural processes, the way things happen with effect and impact and how tensions and conflicts give rise to forms and embody resistance. These properties are so present and pervasive in reality, so manifest and subtle, yet very difficult to describe - much like the experience of consciousness itself. One aspect of energy's active, dynamic nature is its causal efficacy, as some physicists and biologists have recognised: 'Energy may be called the fundamental cause for all change in the world' (Heisenberg, 1958). The absorption of electromagnetic energy from the sun by the matter on earth supplies the motive force needed to drive chemical reactions that sustain life and is likely to have been instrumental in the formation of life (Boltzmann, 1886; Morowitz, 1979; Morowitz and Smith, 2007). High-grade energy is required to maintain biological systems at states of non-equilibrium with their surroundings and resist the tendency towards entropy (Schrödinger, 1944). The second law of thermodynamics mandates that free energy - the energy in a system available to do work, i.e., moving something against an opposing force - will minimize or tend towards equilibrium. This principle has been expressed as 'nature abhors a gradient' (Schneider and Sagan, 2005). The more complex and higher performing the system, the greater the free energy is required to maintain it (Chaisson, 2001). 
We now understand that there are two main forms of energy: kinetic and potential. Kinetic energy is the property of objects in motion, while potential energy inheres in objects by virtue of their relative position or configuration. All other forms of energy, such as thermal, electromagnetic, solar, chemical, gravitational, atomic and so on are in themselves forms of either kinetic or potential energy (Smil, 2008; Rennie, 2015). While much can be said about kinetic and potential energy, I want to draw attention here to the fact that they are both manifestations of difference. Kinetic energy expresses difference due to a change in motion across time. Potential energy expresses difference due to tension or through attraction or repulsion across space. Using Heraclitean concepts, we might say that energy (fire) consists of motion (change) and tension (conflict), both being expressions of difference (Heisenberg, 1958). Neither kinetic nor potential energy inhere absolutely in objects but are relativistic properties; motion or change is measured relative to a frame of reference, and tension or conflict is measured between one object and another. The concept of difference then is of utmost importance when considering the nature of energy.

\section{What is information?}

Contemporary science relies heavily on the concept of information. It is referred to as the basic property of nature, and, sometimes, as the most basic property of nature (Davies, 2010). From neuroscientists, we read: 'the brain is fundamentally an organ that manipulates information' (Sterling and Laughlin, 2017). But unlike energy, the concept of information remains ill-defined in science (Capurro and Hjørland, 2005) and is difficult to isolate from observer-dependent subjectivity (von Foerster, 2003; Deacon, 2010; Werner, 2011; de-Wit et al., 2016). The term is sometimes used 'intuitively' (Erra et al., 2016) and where one might expect to find a definition, such as in a dictionary of physics, biology or chemistry, none appears (Rennie, 2015; Hine, 2015; Rennie, 2016). James Gibson was sceptical about the prolific use of the term in science (Gibson, 1974; Gibson, 1986). The most widely cited formal definition is the one given by Claude Shannon (1948) and developed by Shannon and Weaver (1949) in their mathematical theory of communication. To Shannon and Weaver, information is a measure of uncertainty in a sequence of binary digits sent between a transmitter and a receiver. In his original paper, Shannon explicitly stated that his theory had nothing to say about any meaning contained in the message or about how it is interpreted by the receiver. And because it is a measure - a description of a physical process - Shannon and Weaver's definition of information has no causal efficacy in the world. It is a product of mental activity rather than a cause.

Integrated Information Theory (IIT) also relies heavily on the concept of information, but Tononi and colleagues provide no formal definition (Oizumi et al., 2014). Instead they distinguish between extrinsic and intrinsic information. Extrinsic information is the same as the definition of information given by Shannon and Weaver. It is an objectively measurable property of a system that can only be assessed by an external observer from outside the system. IIT, on the other hand, refers to intrinsic information, which '...is assessed from the intrinsic perspective of a system in terms of the differences that make a difference to it'. Intrinsic information has causal power because it changes the system of which it is an integrated part. Moreover, intrinsic information is meaning defined as a 'maximally irreducible conceptual structure' (MICS) instantiated in a system such as the brain. The MICS does not encode meaning so that it can be transmitted through a channel to be interpreted by an agent elsewhere. Rather, it is the way it is organized as a shape, in concept space, that constitutes the meaning itself. Oizumi et al. give an example of a 
neuron that fires when stimulated by a face. This event can be observed externally only as a correlation between stimulation and activation. From the point of view of the neuron's owner, however, the meaningfulness of the experience of seeing the face inheres in the neural action itself and the way it modifies the shape of the structure within which it functions.

The description of intrinsic information given by Oizumi et al. has more in common with energy, as described above, than it does with classical information, as defined by Shannon and Weaver. Like intrinsic information, energy is causally efficacious and inherently differential. We saw that energetic activity is manifest as differences, either of motion or tension, and that due to their active, impactful, forceful nature, these differences have effects on the systems in which they are a part. All information carrying systems we encounter in the world, whether binary digits in a computer or photodiode switches, are physically manifested as differentiated states of energy (for example, voltages) that require a minimal amount of energy to modify (Landauer, 1961). Recent experiments have confirmed this principle and demonstrated the intimate link between information and energy (Bérut et al., 2012). In fact, when Gregory Bateson defined information as 'any difference which makes some difference in a later event', he was explicitly referring to the way cybernetic systems activate and self-regulate using differences between states of energy: 'What we mean by information - the elementary unit of information - is a difference which makes a difference, and it is able to make a difference because the neural pathways along which it travels and is continually transformed are themselves provided with energy' (Bateson, 1972. Emphasis in original).

Perhaps the most conceptually challenging aspect of intrinsic information as described by Oizumi et al. is the claim that meaning inheres in the irreducible structure of the system itself. How could it be that a certain organization of neural activity endows the owner of the neurons with the capacity to appreciate meaning, that is, to have conscious experience? This, of course, is the central and most profound problem facing those wishing to understand the place of consciousness in nature. Framing the problem within the terms of information theory, which reduces all processes to an abstract binary sequence in a computing machine, has not so far yielded an explanation. Reframing it within the context of energetic activity in natural biological systems may prove more productive.

\section{The place of consciousness in nature}

How does thinking about energy help us to understand the place of consciousness in nature? In his book Art \& Perception, the psychologist and art historian Rudolph Arnheim tried to convey the dynamic play between the motion and tension underlying art composition and appreciation. He offered the image of a rope being pulled by two equally strong men: 'It is still, but loaded with energy' (Arnheim, 1969). To an observer, the rope has, what we might call, extrinsic energy. An observer can measure the energetic processes at work, the forces, tensions, impacts and so on, but can account for them only as a list of abstract values. From the perspective of the rope, however, things feel different. The intrinsic energy in the rope is doing the work of stretching, of being in the state of tension and arrested motion. This state is not reducible to any subordinate property within the system but is a product of the whole system being in the state it is in at the time it occurs. We might say, following the philosopher Thomas Nagel's definition of subjective experience, that there is 'something it is like' to be the rope in this intrinsic energetic state 
(Nagel, 1974). This 'something it is like-ness' is available only to the rope under these conditions; we, as observers, cannot 'feel' it the way the rope does.

We have seen that the brain is an energy processing system of unimaginable complexity. Its biological structure - the ultrafine networks of neurons, astrocytes and blood vessels, its neurotransmitters and ion channels - serve to distribute and convert energy in fantastically intricate ways. When an action potential in a neuron moves an impulse along an axon, for example, it consumes (converts) energy to do the work of creating a difference in voltages within the cell that makes the movement possible. This work is achieved through a delicate balance of ionic gradient potentials regulated by chemical mechanisms that must be continually resupplied with energy from the blood. Taken in its totality, the brain is activated by vast assemblies of energetic differences integrated into an exquisitely organized structure, the maintenance of which comes with a high metabolic cost. But these differences are not abstract binary codes in a computational or informational theoretic sense. Numbers have no causal efficacy. Energetic differences in the brain are active, actualized, in motion or in tension. They exert and respond to force and expend effort through work. They are the 'differences which make a difference' precisely because they, like all energetic processes, have causal efficacy on each other and on the process of the system as a whole.

The primary function of an organism's nervous system, besides internal regulation, is to control its behavioural response to its environment. This includes being able to move towards mates or sources of nutrition and away from noxious environments or predators. The mechanisms supporting this behaviour can be seen at work in organisms with relatively simple nervous systems, such as the C. elegans worm (Sterling and Laughlin, 2017). Chemical gradients in the environment activate chemosensory neurons on the worm's surface that connect via interneurons to motor neurons that control the action of dorsal and ventral muscles, which, in turn, control the worm's movement (de Bono and Maricq, 2005). In this way, differences in the chemical potential energy in the environment are converted into differences of electrochemical potential energy in the organism and then into differences of kinetic energy in the muscles, which, by antagonistic action, result in the kinetic energy of the organism's movement. There is no reason to not think that the same essential principle is at work in a system of far greater complexity such as the human nervous system. The evolutionary benefit of vision is the capacity it confers on the seeing organism to effectively guide action in light of environmental conditions, achieved through an intricate sequence of energy conversions. The fact that our complex biology supports so rich a repertoire of sensory differentiations and motor responses may only be a difference of degree rather than of kind with the humble worm.

We can now address the two questions posed in the introduction. First, how is it that we experience visual sensation? When I study the content of my visual field, as depicted in Figure 1, I find myself confronted with a variegated array of colours, textures and levels of luminance. The field seems to be composed of many fine-grained bursts of activity, rubbing up against each other, clashing and jiggling, yet at the same time organized into larger, more coherent forms that act both antagonistically and in concert to define the layout of the space as a whole. My visual consciousness consists of a sum of differences composed not of isolated features but of relational contrasts: more light in one part of the visual field compared to another, more green than red or more homogeneity in this region than that. We saw how this sum of differences might conceivably be instantiated as a physical system in the grid model described in section 6 . In order for my visual experience 
to occur, countless conduits of energy are ceaselessly at work within my brain, burning the copious amounts of fuel needed to drive the motion and sustain the tension from which my experience is woven. Evidence discussed above suggests that it is not the sheer volume of energy or its distribution in the brain that determines my conscious state, but the intricacy of its organization. What I am experiencing directly is the organized activity of the intrinsic energy in my brain and in my body. There is something it is like to be the countless motions and tensions at work in my biological system.

Second, why do we experience visual sensation from our own subjective point of view? The visual sensation depicted in the painting appears uniquely to me from my perspective because my visual apparatus acts not so much as a detector of objective differences 'out there' (environmentally) but as a generator of discontinuities or discriminations 'in here' (intra-cerebrally). The environment and the experience are correlated in a way that usefully serves certain biological needs such as guiding action, but they are not identical. The differences in light intensity and wavelength I experience between the window and the floor, for example, are not, in any simple way, properties of the world itself. They only come into being for me through the agency of my visual sensation from within my particular perspectival frame. Moreover, we are beginning to understand the extent of the contribution made to visual experience by intrinsic brain activity and predictive processing, where perceptual decisions can be made in the absence of or in expectation of environmental stimulation (Raichle, 2011; Panichello et al., 2013). My visual experience of the world, then, is a product of my generating patterns of integrated energetic differences within my own biological system that are causally but indirectly correlated to environmental energetic differences that impinge on my sensory receptors. This experience belongs to me because I am creating it; in many ways I am it.

In a series of lectures given in 1937-8, collected in a volume called 'Man on his Nature', Charles Sherrington considered the relationship between energy and mind (Sherrington, 1940). Drawing on the physics of his day, he understood all physical matter to be composed of forms of energy. But he could not conceive how the mind arises from energetic processes: 'The energy-concept of Science collects all so-called 'forms' of energy into a flock and looks in vain for the mind among them'. The mystery was deepened for him by the knowledge, then emerging through studies of electrical and metabolic activity in the brain, of how intimately energy and the mind must be linked. He was compelled to wonder, 'Is the mind in any strict sense energy?' but reluctantly concluded that, 'thoughts, feelings, and so on are not amenable to the energy (matter) concept', and, therefore, lie beyond the purview of natural science despite the embarrassment this causes for biology.

The evidence and arguments presented here may have offered Sherrington some hope that this troubling rift in our knowledge of natural phenomena can be healed. I have shown that it is plausible to conceive of the operation of the mind, including conscious awareness, in terms of energetic processes instantiated in brains. Doing so requires that we rethink our understanding of energy and appreciate what Aristotle was trying to express with the concept of energeia. In whatever way we translate that term - whether as action, actuality, actualization, energy or being-at-work - the general thrust is the same: work is being done. Work entails movement against resistance, and this entails tension. Sherrington understood that: 'Energy acts, i.e. is motion,' but went on: 'of a mind a difficulty is to know whether it is motion'. The thesis presented here postulates that consciousness is the product of a fantastically complex organization of motional and tensional differences. 
If we are to naturalise consciousness, we must find a place for energy in the mind or for the mind in energy.

\section{A scientific hypothesis}

From the available neurobiological evidence, it is clear that a constant supply of energy to the brain is necessary for doing the work of sustaining consciousness. However, it is not the sheer volume of energy in the brain or its localization that determines whether consciousness will be present. What seems critical is the complexity of its organisation. The hypothesis presented here is that a certain organisation of energy is sufficient for sustaining consciousness and that states of energetic complexity will causally determine states of awareness. What marks out one state of consciousness from another (say between intense attention and daydreaming) or one level of consciousness from another (say between a healthy person and one in a minimally conscious state) or one kind of consciousness from another (say between a human and a dolphin) may directly depend on the structure and complexity of the energetic differences being integrated. If so, this ought to be measureable, just as Tononi measured $\Phi$ and others have measured the PCI or wSMI. This hypothesis can be tested, and not necessarily in living brains. If a mechanical system, which is able to generate patterns of energy distribution with varying complexity of differentiation and integration could be devised, and a measure of degree of sentience, even if rudimentary, in any such system could be agreed on, then it could be tested whether varying the amount of energetic complexity determined the level of sentience within the system. The prediction is that any system having the necessary level of energetic differentiation and integration will suffice as being conscious.

\section{A potential therapeutic benefit}

Significant numbers of people suffer from disorders of consciousness and other health problems related to impaired brain function (Georgiopoulos et al., 2010). Without full understanding of how brain functions determine our conscious experience, we are prevented from developing new and effective diagnoses and treatments for consciousness related disorders. If it turns out that, as proposed here, conscious experience is determined by the circulation and organization of energy in the brain, then this could help in developing pharmacological and other interventions of potential benefit to patients.

\section{Conclusion}

Consciousness is a topic of dizzying complexity and much - perhaps too much - has been written about it. Scientific research, especially that conducted over the last couple of decades, has substantially improved our knowledge of the relationship between brain processes and conscious experience, and some of this work has been discussed here. But the problem of how to scientifically account for the fact of experience remains unresolved. Some have claimed it may be not be explicable as a physical or physiological process at all (Chalmers, 1996). I have argued that we need to consider the role of energy in the production of conscious experience. Energy has generally been assigned a subordinate role to information, as providing the power needed to drive neural signalling and computation. But this view is perhaps based on too limited an understanding of what energy is and too much faith in the explanatory and causal power of information. 
Conscious experience, at least in the case of the immediate awareness of the visual field, can be characterized as being both differentiated and integrated, as Tononi and others have postulated (e.g. Edelman et al., 2011). As we follow the process of energetic activity from environmental light to retinal stimulation to neural excitation we can identify a functional principle in which energetic differences in the environment lead to energetic differences in the neural fabric of the visual system that are indirectly but usefully correlated. Based on this view, the function of energy in the brain is not, as is widely held, to provide fuel so that neurons can signal and process information. Rather, the role of neurons and other related structures, such as astrocytes, is to channel energy through spasmodic bursts of activity in highly organized structures that drive behaviours critical to survival, such as action.

The complexity of these organized structures, as can be measured using information-theoretical techniques, will vary within individuals and across species. Recent evidence suggests that a critical level of complexity is necessary to sustain consciousness, dubbed PCI or $\Phi^{\max }$ and characterized by high levels of differentiation and integration. This work points to a strong correlation between the presence of phenomenal experience and observable properties of the brain. The long-standing problem in science and philosophy of mind, however, has been how to progress from correlation to causation. The energetic thesis proposed here sets out a causal connection between observable activity in the brain and the consciousness we experience.

Energy is more than the abstract accounting measure often referred to in physics and chemistry. It has causal power, it acts, it moves, it tenses, it drives work. The proposal is that sensation, feeling, experience, the sense of being, the diversity and vividness of seeing are the effects of actualized motion and tension churning through the matter of the brain. Yet while such processes occurring in the human brain may be unmatched in organizational complexity, they should be no different in principle to processes occurring elsewhere in nature.

\section{Acknowledgements}

\section{References}

Abbott, M., and Van Ness, C. (1972). Theory and Problems of Thermodynamics, by Schaum's Outline Series in Engineering. New York: McGraw-Hill Book Company.

Aboy, M., Hornero, R., Abasolo, D., and Alvarez, D. (2006) Interpretation of the Lempel-Ziv Complexity Measure in the Context of Biomedical Signal Analysis. IEEE Trans. Biomed. Eng. 53(11), 2282-2288.

Alkire, M.T. (1998). Quantitative EEG Correlations with Brain Glucose Metabolic Rate during Anesthesia in Volunteers. Anesthesiology. 89(2), 323-333.

Allaman, I., and Magistretti, P. (2013). "Brain energy metabolism," in Neuroscience in the $21^{\text {st }}$ Century, ed. D. Pfaff (New York: Springer), 1591-1620.

Allen, J. (2009). The Lives of the Brain: Human Evolution and the Organ of the Mind. London: Harvard University Press. 
Alyssa, A., and Brian, B. (2012). "Visual field map organization in human visual cortex," in Neuroscience: Visual Cortex - Current Status and Perspectives, eds. S. Molotchnikoff and J. Rouat (InTech) doi: 10.5772/51914.

Alvarez-Linera Prado, J., Rios-Lago, M., Martin-Alvarez, H., Hernandez-Tamames, J. A., Escribano-Vera, J., and Sanches-del-Rio, M. (2007). Functional magnetic resonance imaging of the visual cortex: Relation between stimulus intensity and bold response. Rev Neurol. 45(3), 147-151.

Ames, A. III, Li, Y., Heher, E., and Kimble, C. (1992). Energy metabolism of rabbit retina as related to function: High cost of $\mathrm{Na}+$ transport. J. Neurosci. 12(3), 840-53.

Annila, A. (2016). On the character of consciousness. Front. Syst. Neurosci. 10:27. doi: $10.3389 /$ fnsys.2016.00027

Aristotle (1818). The Rhetoric, Poetic and Nicomachean Ethics of Aristotle (tr. Thomas Taylor), London: James Black and Son.

Aristotle (2002). Metaphysics (tr. Joe Sachs). Santa Fe, NM: Green Lion Press.

Arnheim, R. (1969). Art and Visual Perception. London: Faber and Faber.

Attwell, D., and Gibb, A. (2005). Neuroenergetics and the kinetic design of excitatory synapses. Nature Rev. 6, 841-849.

Attwell, D., and Laughlin, S. (2001). An energy budget for signaling in the grey matter of the brain. J Cereb Blood Flow Metab. 21(10), 1133-45.

Bailey, D., Townsend, D., Valk, P., and Maisey, M. (2005). Positron-Emission Tomography: Basic Sciences. Secaucus, NJ: Springer-Verla.

Baluška, F., and Mancuso, S. (2009). Deep evolutionary origins of neurobiology. Commun Integr Biol. 2,1, 60-65.

Bateson, G. (1972). Steps towards an Ecology of Mind. San Francisco: Chandler Publication Company.

Bazzigaluppi, P., Amini, A. E., Weisspapier, I., Stefanovic, B., and Carlen, P. (2017). Hungry neurons: Metabolic insights on seizure dynamics. Int. J. Mol. Sci. 18(2269).

Bélanger, M., Allaman, I., and Magistretti, P. J. (2011). Brain energy metabolism: Focus on astrocyte-neuron metabolic cooperation, Cell Metab Rev. 14, 724-738.

Bérut, A., Arakelyan, A., Petrosyan, A., Ciliberto, S., Dillenschneider, R., and Lutz, E. (2012). Experimental verification of Landauer's principle linking information and thermodynamics. $\mathrm{Na}$ ture 483, 187-189. doi: 10.1038/nature10872.

Black, J., Sirevaag, A., and Greenough, T. (1987). Complex experience promotes capillary formation in young rat visual cortex. Neurosci. Lett. 83, 351-355.

Bodart, O., Gosseries, O., Wannez, S., Thibaut, A., Annen, J., Boly, M., et al. (2017). Measures of metabolism and complexity in the brain of patients with disorders of consciousness. Neuroimage Clin. 14, 354-362. 
Boltzmann, L. (1886). The Second Law of Thermodynamics. In B. McGinness, ed., Ludwig Boltzmann: Theoretical physics and philosophical problems: Selected writings. Dordrecht, Netherlands: D. Reidel, 1974.

Boord, P.R., Rennie, C.J. and Williams, L. M. (2007). Integrating "brain" and "body" measures: Correlations between EEG and metabolic changes over the human lifespan. J. Integr. Neurosci. 6(1), 205-218.

Bridges, J. W. (1912). Doctrine of specific nerve energies. The Journal of Philosophy Psychology and Scientific Methods. 9(3), 57-65.

Cahan, D. (ed.). (1995). Hermann Von Helmholtz: Science and Culture. Chicago: Chicago University Press.

Capurro, R., and Hjørland, B. (2003). "The concept of information," in Annual Review of Information Science and Technology (ARIST), ed. B. Cronin (Medford, NJ: Information Today, 37), 343-411.

Casali, A. G., Gosseries, O., Rosanova, M., Boly, M., Sarasso, S., Casali, K. R., et al. (2013). A theoretically based index of consciousness independent of sensory processing and behavior. Sci. Transl. Med. 5(198).

Casarotto, S., Comanducci, A., Rosanova, M., Sarasso, S., et al. (2016) Stratification of unresponsive patients by an independently validated index of brain complexity. Ann. Neurol. 80, $718-$ 729

Chaisson, E. J. (2001). Cosmic Evolution: The Rise of Complexity in Nature. Cambridge, MA: Harvard University Press.

Chalmers, D. (1996). The Conscious Mind: In Search of a Fundamental Theory. Oxford: Oxford University Press.

Chatelle, C., Laureys, S., and Schnakers, C. (2011). "Disorders of consciousness: What do we know?" In Characterizing Consciousness: From Cognition to the Clinic? eds. S. Deheane and Y. Christen, New York: Springer.

Chennu, S., Annen, J., Wannez, S., Thibaut, A., Chatelle, C., Cassol, H., et al. (2017). Brain networks predict metabolism, diagnosis and prognosis at the bedside in disorders of consciousness. Brain. 140(8), 2120-2132.

Clark, D., and Solokoff, L. (1999). "Circulation and energy metabolism of the brain," In Basic Neurochemistry: Molecular, Cellular and Medical Aspects, eds. B. Agranoff and G. Siegel (Philadelphia: Lippincott-Raven), 637-670.

Clausberg, K. (2007). "Feeling embodied in vision," in Embodiment and Cognition, eds. J. Krois, M. Rodengren, A. Steidele, and D. Westerkamp (Amsterdam: John Benjamins).

Coopersmith, J. (2010). Energy, the Subtle Concept: The Discovery of Feynman's Blocks from Leibniz to Einstein. Oxford: Oxford University Press.

Collell, G. and Fauquet, J. (2015). Brain activity and cognition: a connection from thermodynamics and information theory. Front. Psychol. 6:818. doi: 10.3389/fpsyg.2015.00818.

Colman, A. (ed.) (2014). Oxford Dictionary of Psychology. Oxford: Oxford University Press. 
Coelho, R. L. (2009). On the concept of energy: History and philosophy for science teaching. Procedia Soc Behav Sci. 1(1), 2648-2652.

Crick, F., and Koch, C. (1995). Are we aware of neural activity in primary visual cortex? Nature. 375(6527), 121-123.

Crick, F., and Koch, C. (2003). A framework for consciousness, Nat. Neurosci. 6(2), 119-126.

Crone, J. S., Ladurner, G., Höller, Y., Golaszewski, S., Trinka, E., and Kronbichler, M. (2011). Deactivation of the default mode network as a marker of impaired consciousness: An fMRI study, PLOS ONE, 6(10).

Davies, P. (2010). "Universe from bit," In Information and the Nature of Reality: From Physics to Metaphysics, eds. P. Davies and N. Gregersen (Cambridge: Cambridge University Press).

Deacon, T. (2010). What is missing from theories of information? In Information and the Nature of Reality: From Physics to Metaphysics, eds. P. Davies and N. Gregersen (Cambridge: Cambridge University Press).

De Bono, M., and Maricq, A.V. (2005). Neuronal substrates of complex behaviors in C. elegans. Annu Rev Neurosci. 28, 451-501.

de-Wit, L., Alexander, D., Ekroll, V., and Wagemans, J. (2016). Is neuroimaging measuring information in the brain? Psychon Bull Rev. 23(5), 1415-1428.

Dehaene, S. (2014). Consciousness and the Brain. Deciphering How the Brain Codes our Thoughts. London: Penguin Books.

Demertzi, A., Antonopoulos, G., Heine, L., Voss, H.U., Crone, J.S., Angeles, C.D.L., et al. (2015). Intrinsic functional connectivity differentiates minimally conscious from unresponsive patients. Brain. 138(9), 2619-2631.

Dinuzzo, M., and Nedergaard, M. (2017). Brain energetics during the sleep-wake cycle. Curr Opin Neurobiol. 47, 65-72.

Duncan, T. (2002). Advanced Physics. London: John Murray.

Delectorskaya, L., Matisse, H., and Monod-Fontaine, I. (1996). Henri Matisse, contre vents at mares: peintures et livres illustrés de 1939 a 1943, Editions Irus et Vincent Hansma.

Edelman, G., Gally, J., and Baars, B. (2011) Biology of consciousness. Front Psychol. 2, 4.

Ellrod, F. E. (1982). Energeia and process in Aristotle. Int Phil Q. XXII(2), 175-181.

Erra, R., Mateos, D., Wennberg, R. and Perez Velazquez, J. (2016). Statistical mechanics of consciousness: Maximization of information content of network is associated with conscious awareness. Phys. Rev. E. 94(5).

Eysenck, H. J. (1942). The experimental study of the 'good Gestalt'? A new approach. Psychol. Rev. 49(4), 344-64.

Eysenck, H.J. (1987). Thomson's 'bonds' or Spearman's 'energy': Sixty years on. Mank. Q. Monogr. 27(3), 259-74. 
Fechner, G. T. (1905). The Little Book of Life After Death (tr. Mary C. Wadsworth). Boston: Little, Brown \& Co.

Feynman, R. (1963). Conservation of Energy, in The Feynman Lectures on Physics, http://www.feynmanlectures.caltech.edu/I_04.html (accessed 21st December 2017).

Feynman, R. (1985). QED: The Strange Theory of Light and Matter. London: Penguin Books.

Fiser, J., Chiu, C. and Weliky, M. (2004). Small modulation of ongoing cortical dynamics by sensory input during natural vision. Nature, Sep 30;431(7008):573-8.

Friston, K. (2013). Consciousness and hierarchical inference, Neuropsychoanalysis. 15(1), 38 42.

Gay, P. (1988). Freud: A Life for Our Time. London: W. W. Norton \& Co.

Georgiopoulos M., Katsakiori P., Kefalopoulou Z., Ellul J., Chroni E., and Constantoyannis C. (2010). Vegetative state and minimally conscious state: A review of the therapeutic interventions. Stereotact Funct Neurosurg. 88,199-207.

Gibson, J. J. (1950) The Perception of the Visual World. Boston: Houghton Mifflin.

Gibson, J. (1974). Lecture at Ohio State University, 23 May, 1974. Online at: https://www.youtube.com/watch?v=hwRxUyuQEgc. Accessed $25^{\text {th }}$ April 2018.

Gibson, J. J. (1986). The Ecological Approach to Visual Perception. New York: Psychology Press.

Gregory, R. (ed.) (2004). The Oxford Companion to the Mind. Oxford: Oxford University Press.

Gur, M. (1989) Color and brightness fade-out in the ganzfeld is wavelength dependent. Vision Res. 29(10), 1335-1341.

Hameroff, S., and Penrose, R. (2014). Consciousness in the universe: A review of the 'Orch OR' theory. Phys. Life Rev. 11(2014), 39-78.

Heeger, D. J. (2017). Theory of cortical function. PNAS. 114(8), 1773-82.

Heisenberg, W. (1958). Physics and Philosophy: The Revolution in Modern Science. New York: Harper \& Brothers Publishers.

Helmholtz, H. (1866). Handbuch der physiologischen Optik. Volume III. Leipzig: Leopold Voss.

Hine, R. (ed.) (2015). Oxford Dictionary of Biology. Oxford: Oxford University Press

Hoffman, D., Singh, M., and Prakash, C. (2015). The interface theory of perception. Psychon Bull Rev. 22(6), 1480-1506.

Hu, S., Stead, M., Liang, H., and Worrell, G.A. (2009). Reference signal impact on EEG energy. Advances in neural networks - ISNN 2009 Lecture Notes in Computer Science, 605-611.

Hubel, D., and Livingstone, M. (1987). Segregation of form, color, and stereopsis in primate area 18. J. Neurosci. 7:3378-3415. 
Ingvar, D.H. (1971) Cerebral blood flow and metabolism related to EEG and cerebral functions. Acta Anaesthesiol Scan. 15, 110-114.

Loring, D. (2015). INS Dictionary of Neuropsychology and Clinical Neurosciences.

James, W. (1907). The energies of men. Philos. Rev, 16(1), 1-20.

Jung, C. (1969). "On psychic energy," in Collected Works of C.G. Jung, Volume 8: Structure \& Dynamics of the Psyche, eds. G. Adler and R. Hull. Princeton: Princeton University Press.

Kahn, C. H. (1989). The Art and Thought of Heraclitus. Cambridge: Cambridge University Press.

Kanizsa, G. (1974). Contours without gradients or cognitive contours? Gironale Italiano di Psicologia, 9, 93-113.

Koch, C. (2012). Consciousness: Confessions of a Romantic Reductionist. Cambridge, MA: MIT Press.

Koch, C., Massimini, M., Boly, M., and Tononi, G. (2016). Neural correlates of consciousness: Progress and problems. Nature Rev Neurosci. 17, 307-321.

Koenderink and van Doorn. (2008). The structure of visual spaces. J Math Imaging Vis, 31 171187.

Koenderink, J. (2014). The all-seeing eye? Perception. 43, 1-6.

Koponen, L. M., et al. (2015). Minimum-energy coils for transcranial magnetic stimulation: Application to focal stimulation. Brain Stimul. 8(1), 124-134.

Kuschinsky, W. (1993). Is the EEG correlated with the brain metabolism and cerebral blood flow? Basic Mechanisms of the EEG. 109-119.

Landauer, R. (1961). Irreversibility and heat generation in the computing process. IBM J Res Dev. 5(3), 183-191.

Laughlin, S. (2001). Energy as a constraint on the coding and processing of information. Curr Opin Neurobiol. 11, 475-80.

Laughlin, S. B., and Attwell, D. (2005). "Neural energy consumption and the representation of mental events," in Brain Energetics and Neuronal Activity: Applications to fMRI and Medicine, eds. R. G. Shulman and D. L Rothman (Chichester: John Wiley \& Sons).

Laureys, S., Goldman, S., Phillips, C., Bogaert, P. V., Aerts, J., Luxen, A., et al. (1999). Impaired effective cortical connectivity in vegetative state: Preliminary investigation using PET. NeuroImage. $9(4), 377-382$.

Laureys, S. (2005) The neural correlate of (un)awareness: Lessons from the vegetative state. Trends Cogn. Sci. 9(12), 556-559.

Laureys, S., Lemaire, C., and Maquet, P. (1999). Cerebral metabolism during vegetative state and after recovery to consciousness. J Neurol, Neurosurg Psychiatry. 67, 121-133.

Levine, M. (2000). Fundamentals of Sensation and Perception. $3^{\text {rd }}$ Edition. Oxford: Oxford University Press. 
Loring, D. ed. (2015). INS Dictionary of Neuropsychology and Clinical Neurosciences. Oxford: Oxford University Press.

Manning, A. G., Khakimov, R. I., Dall, R. G., and Truscott A. G. (2015). Wheeler's delayedchoice gedanken experiment with a single atom. Nat. Phys. doi: 10.1038/nphys3343

Marr, D., and Hildreth, E. (1980). Theory of edge detection. Proc R Soc Lond [Biol] [Online]. 207(1167), 187-217.

Morcom, A. M., and Fletcher, P. C. (2007) Does the brain have a baseline? Why we should be resisting a rest, NeuroImage, 37(4), 1073-1082.

Mach, E. (1897). Analysis of the Sensations (tr. C. M. Williams). Chicago: Open Court Publishing Company.

Magistretti, P. (2013). Food for thought: What fuels brain cells? Report for Dana Alliance. Accessed 27/3/18. http://www.dana.org/Publications/ReportOnProgress/Food_for_Thought_What_Fuels_Brain_Cells_/

Magistretti, P. J. (2008). "Brain energy metabolism," in Fundamental Neuroscience, eds. Squire et al. (Burlington, MA: Elsevier).

Marcus, G. (2015). The Computational Brain, in Marcus, G. \& Freeman, J., The Future of the Brain. Princeton: Princeton University Press, pp. 205-215.

Messick, J.M., Casement, B., Sharbrough, F.W., Milde, L.N., Michenfelder, J.D., and Sundt, T.M. (1987). Correlation of regional Cerebral Blood Flow (rCBF) with EEG changes during isoflurane anesthesia for carotid endarterectomy. Anesthesiol. 66(3), 344-349.

McCulloch, W., and Pitts, W. (1943). A logical calculus of the ideas immanent in nervous activity. Bull Math Biophys. 5(4), 115-133.

Morowitz, H. (1979). Energy Flow in Biology. Woodbridge: Conn.: Ox Bow Press.

Morowitz, H., and Smith, E. (2007). Energy flow and the organization of life. Complexity. 13, $51-59$.

Niedermeyer, E., and Lopes da Silva, F. (1987). Electroencephalography: Basic Principles, Clinical Applications, and Related Field. Munich: Urban \& Schwarzenberg.

Oizumi, M., Albantakis, L., and Tononi, G. (2014). From the phenomenology to the mechanisms of consciousness: Integrated information theory 3.0. PLOS. 10(5).

Osterberg, G. (1935). Topography of the layer of rods and cones in the human retina. Acta Ophthalmol. Suppl. 6, 1-103

Otis, L. (2007). Müller's Lab. Oxford: Oxford University Press.

Owen, A., Coleman, M., Boly, M., Davis, M., Laureys, S., and Pickard, J. (2006) Detecting awareness in the vegetative state. Science. 8(313(5792)), 1420.

Palmer, S. (1999). Vision Science: Photons to Phenomenology. Cambridge. Mass.: MIT Press. 
Pai, A., and Heining, M. (2007) Ketamine. Continuing Educ. Anaesth. Crit. Care Pain. 7(2), 5963.

Panichello, M., Cheung, O., and Bar, M. (2013). Predictive feedback and conscious visual experience. Front. Psychol.

Perez Velazquez, J. (2009). Finding simplicity in complexity: General principles of biological and non- biological organization. J Biol Phys. 35(3), 209-221.

Pepperell, R. (1995). The Posthuman Condition: Consciousness Beyond the Brain. Bristol: Intellect Books.

Pepperell, R. (2006). Seeing without objects: Visual indeterminacy and art. Leonardo. 39 (5).

Pepperell, R. (2012). Art and externalism. J. Conscious. Stud. 9(11-12), 107-127.

Pepperell, R. (2015). Egocentric perspective: Depicting the body from its own point of view, Leonardo. 48(5), 424-429.

Pepperell, R. (2016). Where do we see? Perception. 44(51).

Pepperell, R. (2017). "Imaging human vision: An artistic perspective," in Human Vision and Electronic Imaging 2017, eds. B. E. Rogowitz, T. N. Pappas, H. de Ridder (Proceedings of SPIEIS\&T Electronic Imaging).

Pepperell, R. (2018). "Art, energy and the brain," in The Arts and The Brain: Psychology and Physiology Beyond Pleasure (Progress in Brain Research), eds. J. Christensen and A. Gomila (New York: Elsevier).

Phelps, M., Mazziotta, J., Kuhl, D., Nuwer, M., Packwood, J., Metter. J., et al. (1981). Tomographic mapping of human cerebral metabolism: Visual stimulation and deprivation. Neurology. 31(5), 517.

Pirenne, M. (1967). Vision and the Eye. London: Chapman \& Hall.

Purves, et al. (2001). Neuroscience, $2^{\text {nd }}$ edition. Sunderland (MA): Sinauer Associates.

Raichle, M. (2011). "Intrinsic activity and consciousness," in Characterizing Consciousness: From Cognition to the Clinic? eds. S. Deheane and Y. Christen (New York: Springer).

Raichle, M. E., and Snyder, A. Z. (2007). A default mode of brain function: A brief history of an evolving idea. NeuroImage, 37(4), 1083-1090.

Raichle, M. E. (2010). The brain's dark energy. SciAm. March, 44-9.

Rennie, R (ed.). (2015). Oxford Dictionary of Physics. Oxford: Oxford University Press.

Rennie, R (ed.). (2016). Oxford Dictionary of Chemistry. Oxford: Oxford University Press

Riggs, L. A., and Ratliff, F. (1952). The effects of counteracting the normal movements of the eye. J. Opt. Soc. Am. 42, 872-873.

Rose, D. (1986). Learning about energy. New York: Plenum Press. 
Roy, C., and Sherrington, C. (1890). On the regulation of the blood supply in the brain. J. Physiol. 11(1-2).

Schiff, N. D. (2013). Making waves in consciousness research. Sci. Transl. Med. 5(198).

Semon, R. (1921). The Mneme. London: George Allen \& Unwin Ltd.

Seth, A. (2014). What behaviourism can (and cannot) tell us about brain imaging. Trends Cogn Sci. 18(1), 5-6.

Schneider, E., and Sagan, D. (2005). Into the Cool: Energy Flow, Thermodynamics, and Life. Chicago: University of Chicago Press.

Schölvinck, M. L., Howarth, C., \& Attwell, D. (2008). The cortical energy needed for conscious perception. Neuroimage, 40(4), 1460-1468.

Schrödinger, E. (1944). What is Life? The Physical Aspect of the Living Cell. Cambridge: Cambridge University Press.

Shannon, C. (1948). A mathematical theory of communication. Bell Syst Tech J. 27, 379-423, 623-656.

Shannon, C., and Weaver, W. (1949). The Mathematical Theory of Communication. Urbana, IL: University of Illinois Press.

Sherrington, C. (1940). Man on his Nature. London: Pelican Books.

Shulman, R. and Hyder, F. (2005). Brain and Mind: An NMR Perspective. In Shulman, R. and Rothman, D. (eds.) Brain Energetics and Neural Activity. New Jersey: John Wiley \& Co..

Shulman, G. L., Corbetta, M., Buckner, R. L., Fiez, J. A., Miezin, F. M., Raichle, M. E., et al. (1997). Common blood flow changes across visual tasks: I. Increases in subcortical structures and cerebellum but not in nonvisual cortex. J. Cog. Neurosci. 9(5), 624-647.

Shulman, R., Hyder, F., and Rothman, D. (2009). Baseline brain energy supports the state of consciousness. PNAS. 106(27), 11096-11101.

Shulman, R. G. (2013). Brain Imaging: What It Can (and Cannot) Tell Us About Consciousness. Oxford: Oxford University Press.

Shulman, R. G., and Rothman, D. L. (eds.). (2005). Brain Energetics and Neuronal Activity: Applications to fMRI and Medicine. Chichester: John Wiley \& Sons.

Shulman, R. G., and Rothman, D. L. (eds.). (2005). Brain Energetics and Neuronal Activity: Applications to fMRI and Medicine. Chichester: John Wiley \& Sons.

Shulman, R. G., Hyder, F., and Rothman, D. L. (2014). Insights from neuroenergetics into the interpretation of functional neuroimaging: An alternative empirical model for studying the brain's support of behavior. J Cereb Blood Flow Metab. 34, 1721-1735.

Sibson, N., Dhankhar, A., Mason, G., Rothman, D., Behar, K., and Shulman, R. (1998). Stoichiometric coupling of brain glucose metabolism and glutamatergic neuronal activity. Proc. Natl. Acad. Sci. USA. 95, 316-321. 
Silver, M. A., and Kastner, S. (2009). Topographic maps in human frontal and parietal cortex. Trends Cogn Sci. 13(11), 488-495.

Smil, V. (2008). Energy in Nature and Society: General Energetics of Complex Systems. Cambridge, MA: MIT Press.

Snowden, R. J., Thompson, P., and Troscianko, T. (2012) Basic vision: An introduction to visual perception. Oxford: Oxford University Press.

Song, C., Haun, A., and Tononi, G. (2017). Plasticity in the structure of visual space. eNeuron: Sensory and Motor Systems. (May/June).

Spearman, C. (1950). Human Ability. London: Macmillan.

Srinivasan, R., Russell, D., Edelman, G., and Tononi, G. (1999). Increased synchronization of neuromagnetic responses during conscious perception. J. Neurosci. 19, 5435-5448.

Stender, J., Mortensen, K. N., Thibaut, A., Darkner, S., Laureys, S., Gjedde, A., et al. (2016) The minimal energetic requirement of sustained awareness after brain injury. Curr. Biol. 26(11), 1494-1499.

Sterling, P., and Laughlin, S. (2017) Principles of Neural Design. Cambridge, Mass.: MIT Press.

Strawson, Galen (2008). "Real materialism," in Real Materialism and Other Essays (Oxford: Oxford University Press), 19-52.

Street, S. (2016). Neurobiology as Information Physics. Front. Syst. Neurosci. 10:90. doi: 10.3389/fnsys.2016.00090.

Tononi, G. (2012). Integrated information theory of consciousness: An updated account. Arch Ital Biol. 150, 290-326.

Tononi G (2014). The conscious grid. http://integratedinformationtheory. org/download/conscious_grid.pdf.

Tononi, G., Boly, M., Massimini, M., and Koch, C. (2016). Integrated information theory: From consciousness to its physical substrate. Nat Rev Neurosci. 17, 450-461.

Tozzi, A., Zare, M. and Benasich, A. (2016) New Perspectives on Spontaneous Brain Activity: Dynamic Networks and Energy Matter. Front. Hum. Neurosci. 10:247. doi: 10.3389/fnhum.2016.00247

Treue, S. (2003). Visual attention: The where, what, how and why of saliency. Curr Opin Neurobiol. 13(4), 428-432.

Umberger, B. R., Gerritsen, K. G., and Martin, P. E. (2006). A model of human muscle energy expenditure. Comput Methods Biomech Biomed Engin. 9(5), 342-342.

Vanhaudenhuyse, A., Noirhomme, Q., Tshibanda, L. J.-F., Bruno, M.-A., Boveroux, P., Schnakers, C., et al. (2009). Default network connectivity reflects the level of consciousness in non-communicative brain-damaged patients. Brain. 133(1), 161-171.

Von Foerster, H. (2003). "Notes on an epistemology for living things," in Understanding Understanding: Essays on Cybernetics and Cognition. New York: Springer. 
Werner, G. (2011). Letting the brain speak for itself. Front Physiol. 2.

Wong-Riley, M. (2010). Energy metabolism of the visual system. Eye and Brain. 2, 99-116.

Ziv, J., and Lempel, A. (1977). A universal algorithm for sequential data compression. IEEE Trans Inf Theory. 23(3), 337-343. 